Supporting information

\title{
Oxidized Bis(indolyl)methane: A Simple and Efficient Chromogenic-Sensing Molecule Based on the Proton Transfer Signaling Mode
}

\author{
Xiaoming $\mathrm{He}^{\mathrm{a}, \mathrm{b}}$, Shuzhen $\mathrm{Hu}^{\text {a,b }}$, Kai Liu ${ }^{\mathrm{a}, \mathrm{b}}$, Yong Guo ${ }^{\text {a }}$, Jian Xu ${ }^{\text {a }}$, Shijun Shao ${ }^{\mathrm{a}, *}$ \\ ${ }^{a}$ Key Laboratory for Natural Medicine of Gansu Province, Lanzhou Institute of Chemical Physics, Chinese
} Academy of Sciences, Lanzhou 730000, P. R. China

${ }^{\mathrm{b}}$ Graduate School of the Chinese Academy of Sciences, Beijing 100039, P. R. China

Fax: +86-931-8277088, E-mail: shaoguo@1zb.ac.cn

[**] This work was supported by the National Natural Science Foundation of China (No.20372067).

\section{Synthetic experiment:}

Compound 2:

$\mathrm{KHSO}_{4}(1.25 \mathrm{mmol})$ was added to a mixture of indole $(2.5 \mathrm{mmol})$ and benzaldehyde $(1.25 \mathrm{mmol})$ in dry methanol $(10 \mathrm{~mL})$, and the reaction was stirred at room temperature for $2 \mathrm{~h}$. Then water $(10 \mathrm{~mL})$ was added to quench the reaction, and the aqueous phase was extracted with $\mathrm{CH}_{2} \mathrm{Cl}_{2}(3 \times 10 \mathrm{~mL})$. The organic phase was dried with anhydrous $\mathrm{MgSO}_{4}$, and purified by column chromatography and eluted with ethyl acetate and petroleum ether mixture to afford the product (white solid), 92\%, m.p. $124-125{ }^{\circ} \mathrm{C} . \mathrm{IR}$ (KBr) 3410, 3054, 1634, 1600, 1454, 1092, $743 \mathrm{~cm}^{-1} .{ }^{1} \mathrm{H}$ NMR (400 MHz, $\left.\mathrm{CDCl}_{3}\right) \delta: 7.89$ (br, s, 2H, NH), 7.32-7.38 (m, 6H), 7.26-7.28 (m, 2H), 7.13-7.24 (m, 3H), $6.97(\mathrm{t}, 2 \mathrm{H}), 6.64(\mathrm{~s}, 2 \mathrm{H}), 5.87(\mathrm{~s}, 1 \mathrm{H}, \mathrm{Ar}-\mathrm{CH})$. FAB-MS m/z: $322[\mathrm{M}]^{+}$. 


\section{Compound 1:}

Compound $2(0.5 \mathrm{mmol})$ was dissolved in acetonitrile $(8 \mathrm{~mL})$, DDQ $(0.3 \mathrm{mmol})$ solution of acetonitrile was dropwise and slowly added to the solution. This reaction was allowed for $2 \mathrm{~h}$ and gave a dark red precipitate, which was filtered, washed with $\mathrm{CH}_{3} \mathrm{CN}$, and recrystallized from ethanol, 37\%, m.p.

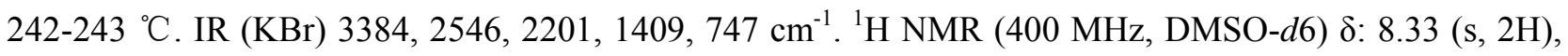
$7.74(\mathrm{t}, 1 \mathrm{H}), 7.6(\mathrm{~m}, 6 \mathrm{H}), 7.27(\mathrm{t}, 2 \mathrm{H}), 7.0(\mathrm{t}, 2 \mathrm{H}), 6.65(\mathrm{~d}, 2 \mathrm{H}) .{ }^{13} \mathrm{C} \mathrm{NMR} \delta: 151.87,147.28,141.83,138.36$, $132.53,131.93,130.47,129.13,127.07,125.38,123.64,122.02,120.94,116.28,114.97,98.38$. HRMS (ESI) $\mathrm{m} / \mathrm{z}\left(\mathrm{M}+\mathrm{H}^{+}\right)$calcd for $\mathrm{C}_{23} \mathrm{H}_{16} \mathrm{~N}_{2}: 321.1386$; found, 321.1383 . 


\section{Spectroscopy}

(1) ${ }^{1} \mathrm{H}$ NMR of compound $\mathbf{1}$
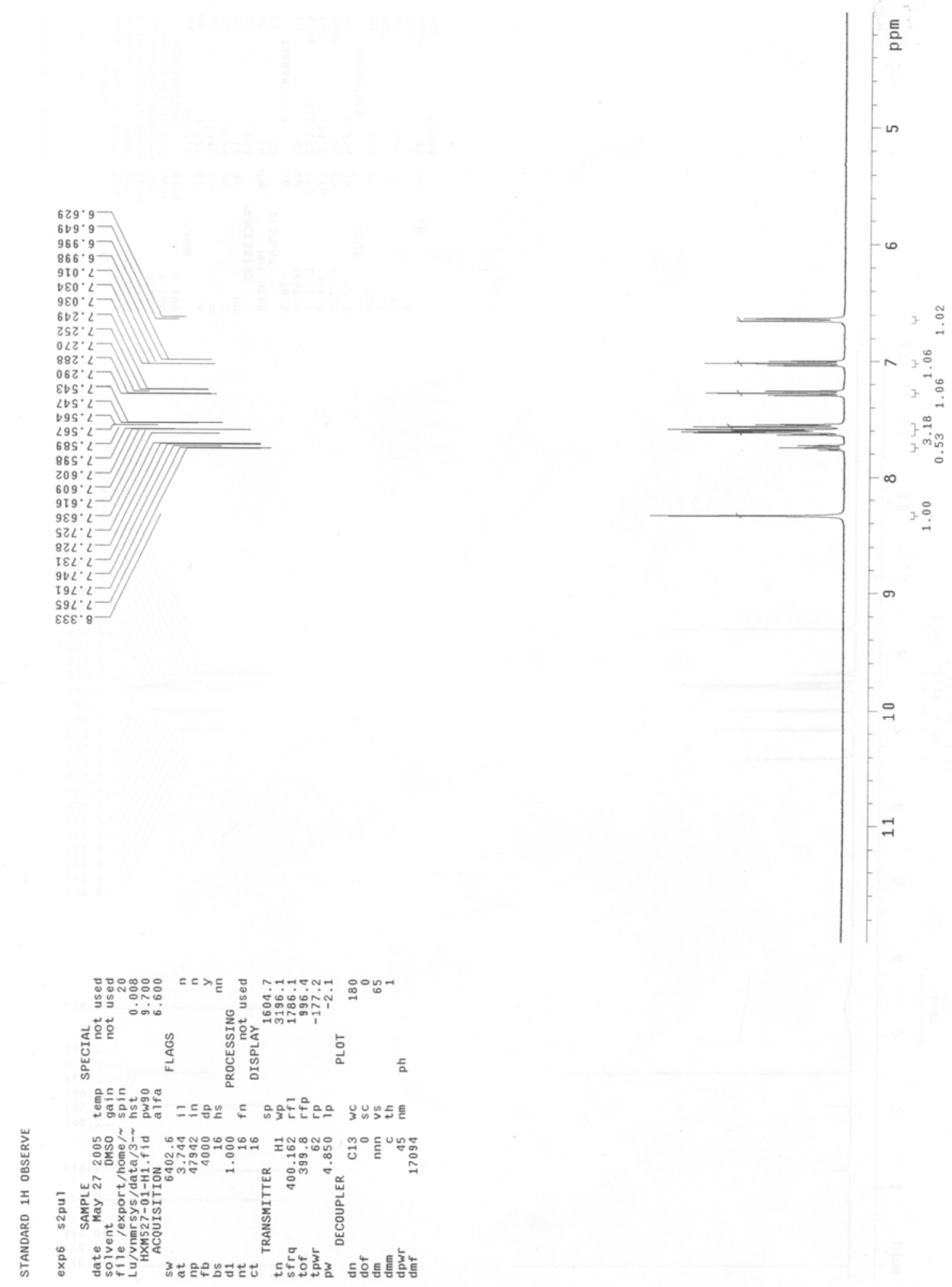
(2) HRMS spectrum of compound $\mathbf{1}$

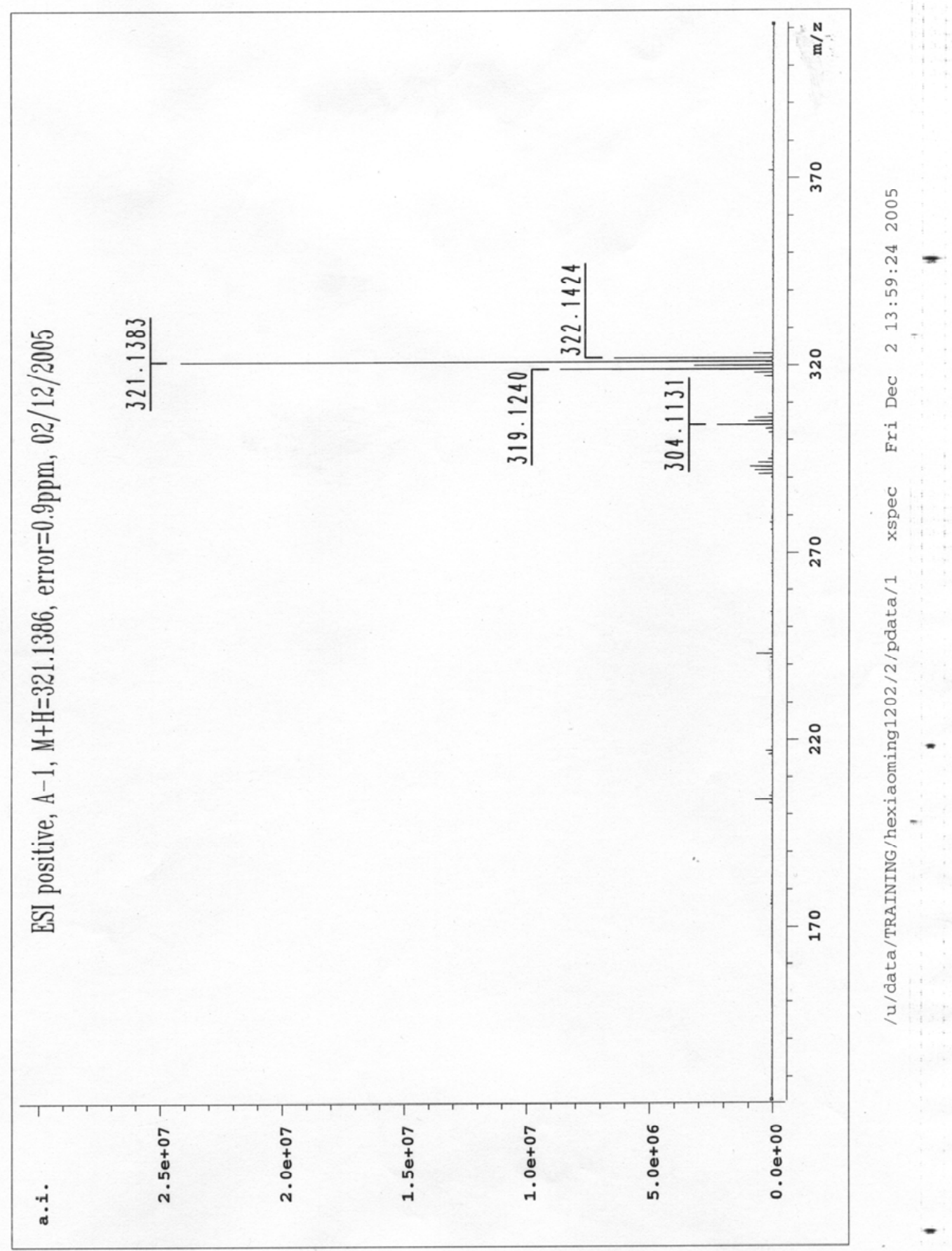


(3) ${ }^{13} \mathrm{C}$ NMR of compound 1

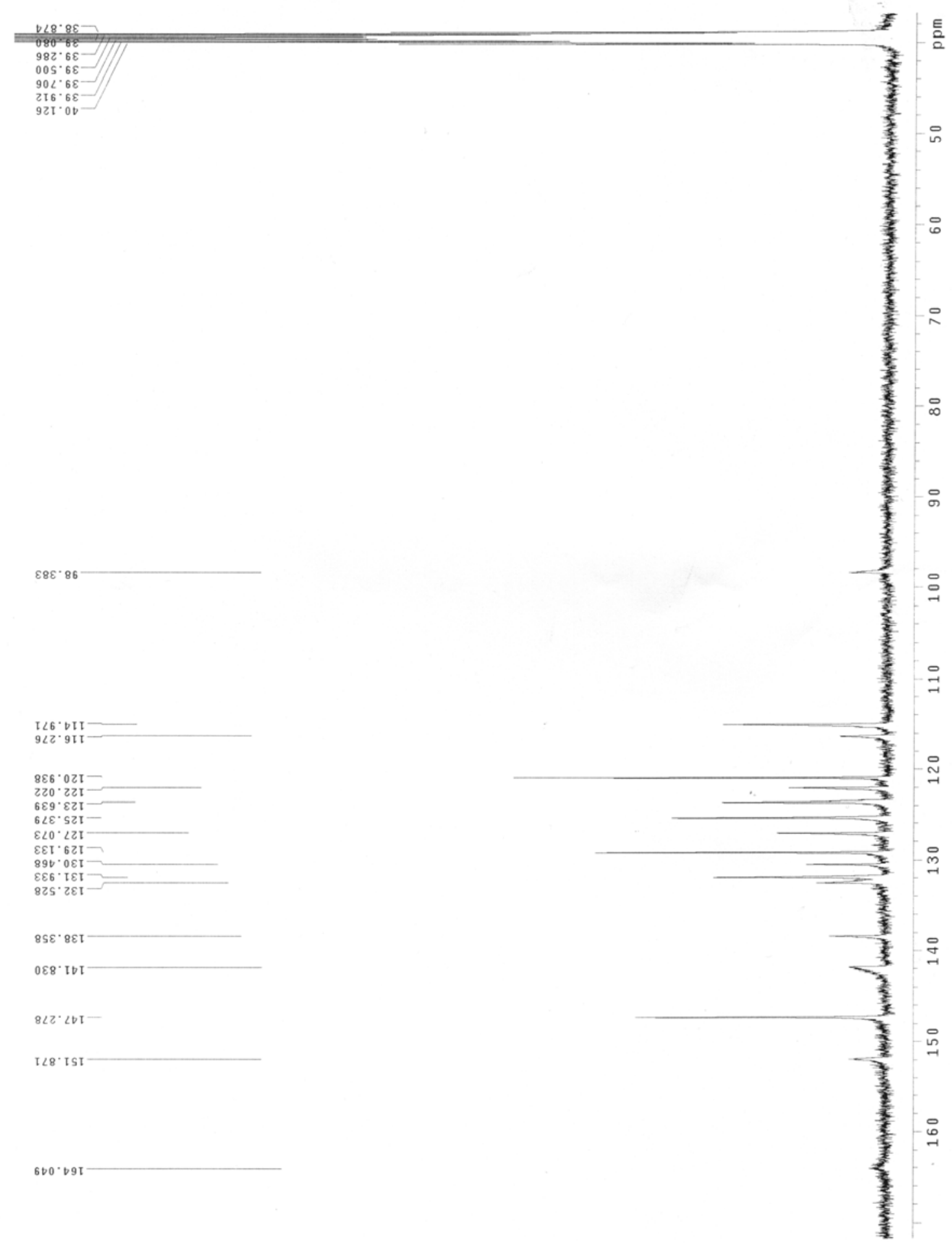


(4) IR spectrum of compound 1

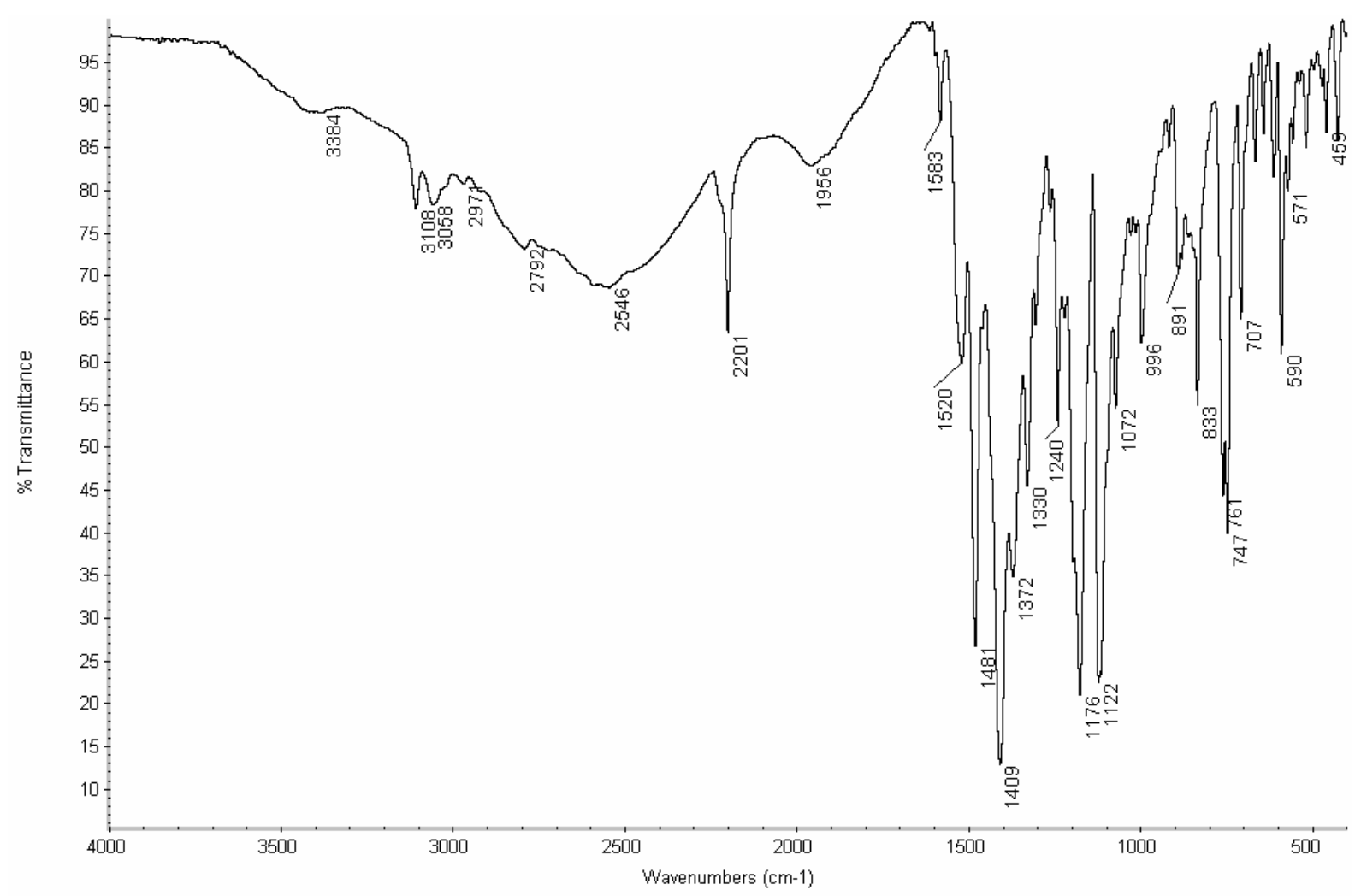


(5) ${ }^{1} \mathrm{H}$ NMR spectra in DMSO-d6 of $\mathbf{1}\left(1.0 \times 10^{-2} \mathrm{M}\right)$ and after addition of various quantities of tetrabutylammonium fluoride.

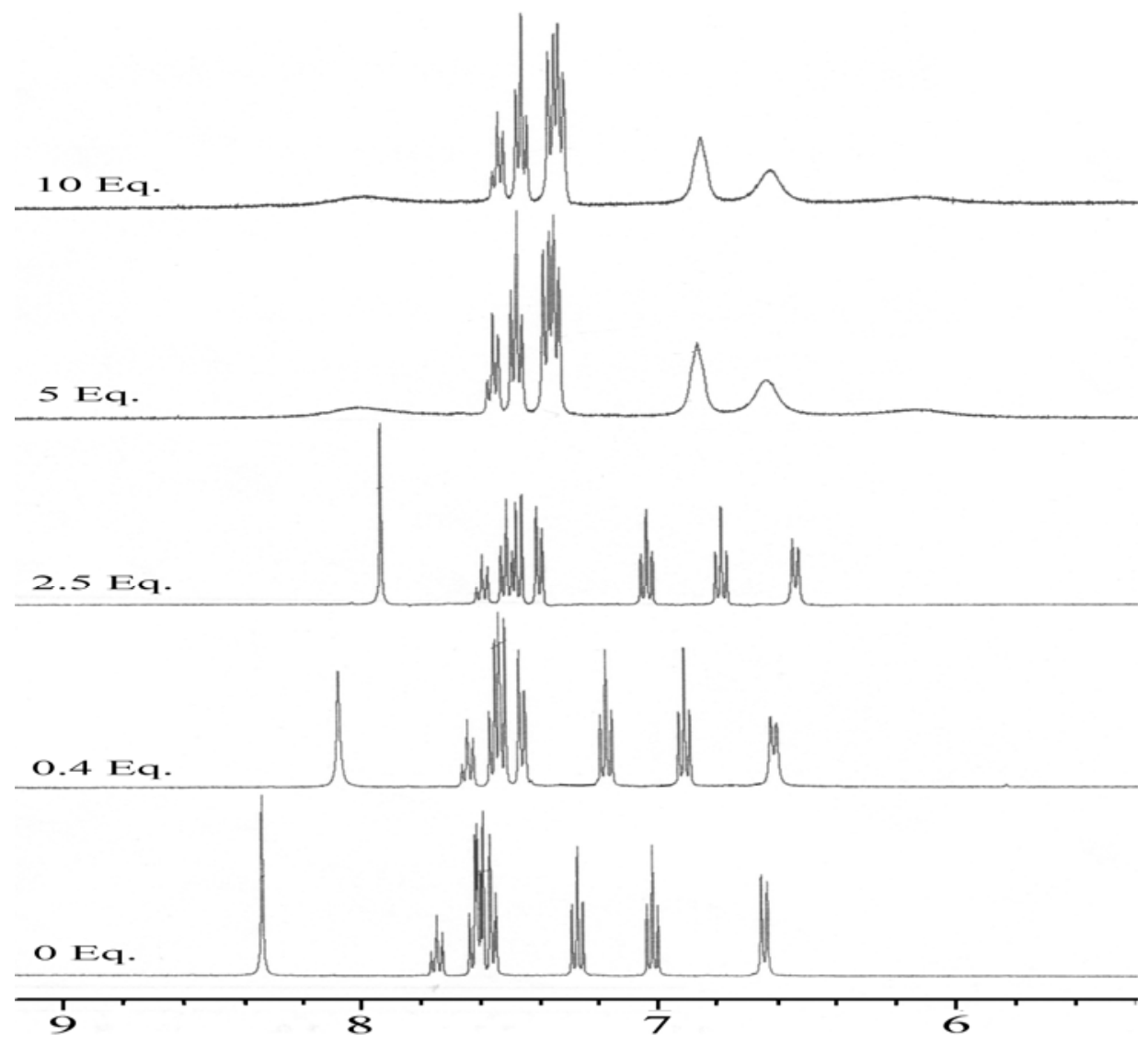


(6) ${ }^{1} \mathrm{H}$ NMR of compound 2

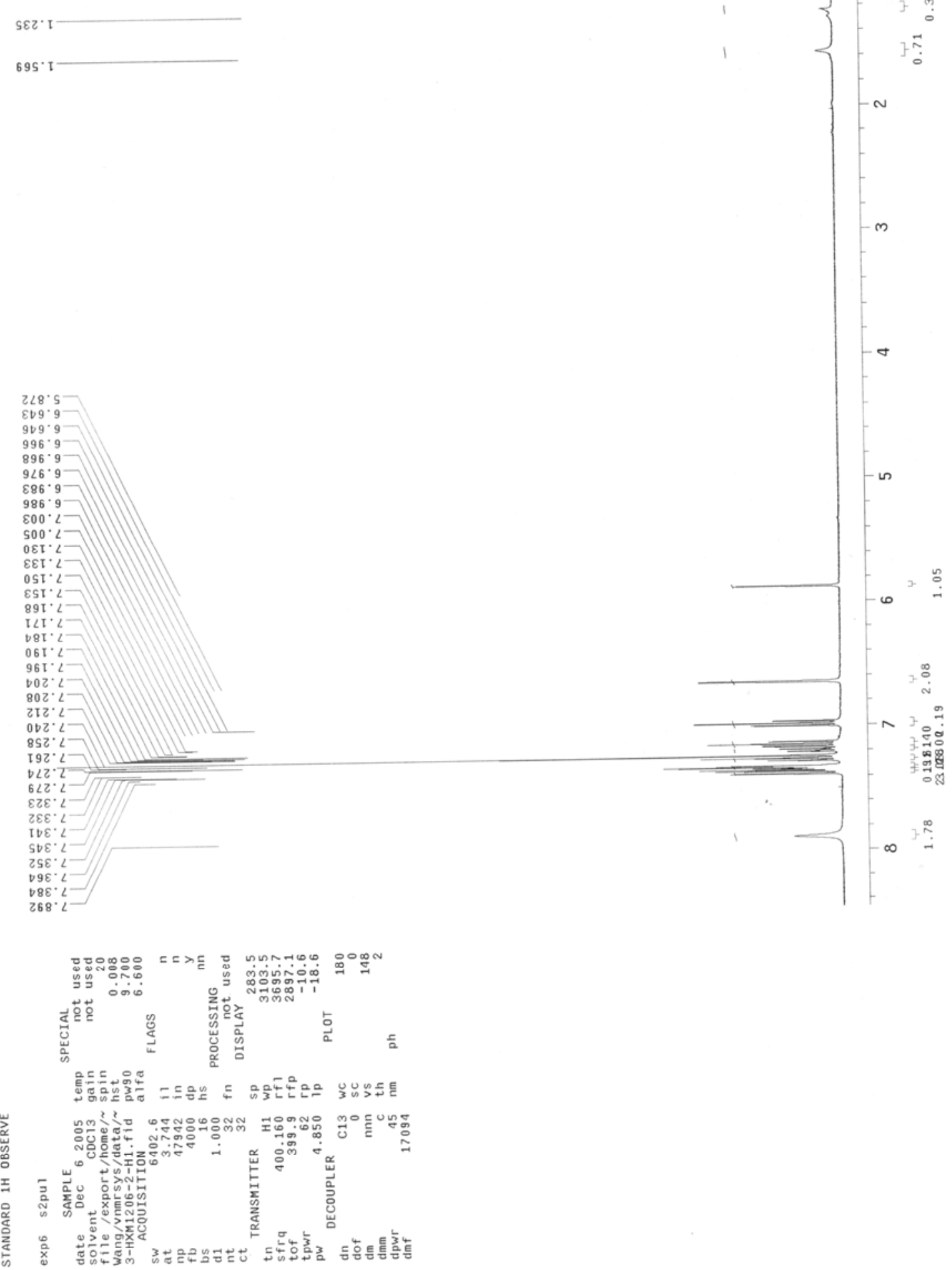


(7) FAB-MS spectrum of compound 2

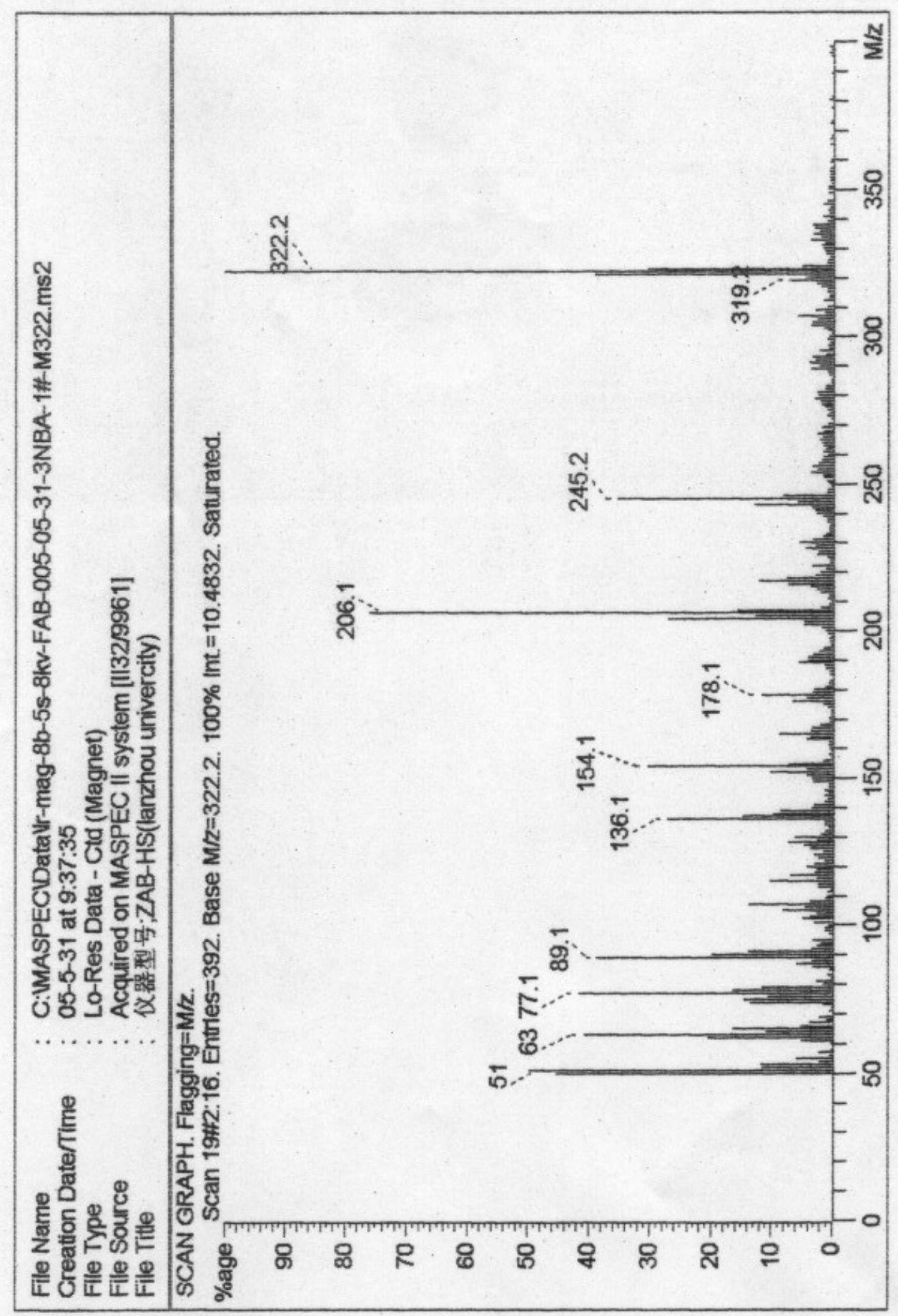


(8) IR spectrum of compound 2

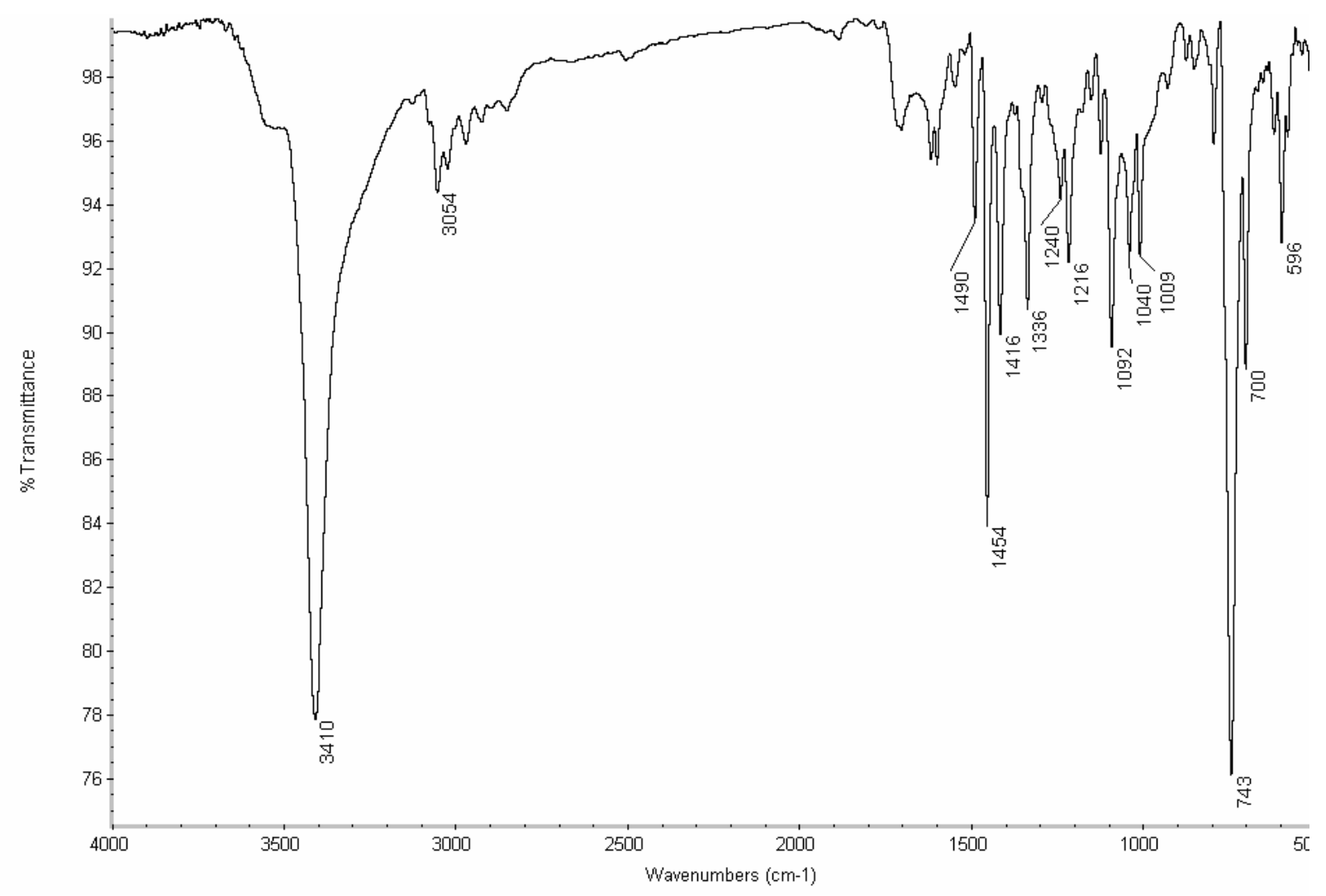

